\title{
Quercetin can reduce insulin resistance without decreasing adipose tissue and skeletal muscle fat accumulation
}

\author{
N. Arias $\cdot$ M. T. Macarulla $\cdot$ L. Aguirre $\cdot$ \\ M. G. Martínez-Castaño $\cdot$ M. P. Portillo
}

Received: 29 May 2013/Accepted: 14 October 2013/Published online: 14 December 2013

(C) Springer-Verlag Berlin Heidelberg 2013

\begin{abstract}
Quercetin exhibits a wide range of biological functions. The first aim of the present work was to analyze the effects of quercetin on fat accumulation in adipose tissue and glycemic control in rats. Any potential involvement of muscle fatty acid oxidation in its effect on glycemic control was also assessed. Animals were fed a high-fat high-sucrose diet either supplemented with quercetin $(30 \mathrm{mg} / \mathrm{kg}$ body weight/day), or not supplemented, for 6 weeks. One week before killing, a glucose tolerance test was carried out. Muscle triacylglycerol content, serum glucose, insulin, fructosamine and free fatty acids were measured, and homeostatic model assessment for insulin resistance (HOMA-IR) was calculated. The activities of lipogenic enzymes and lipoprotein lipase in adipose tissue, carnitine palmitoyl transferase-1b (CPT-1b) and citrate synthase in skeletal muscle, and the expression of several genes, ACO, CD36, CPT-1b, PPAR- $\alpha$, PGC- $1 \alpha, \mathrm{UCP}_{3}$, TFAM and COX-2 in skeletal muscle were analyzed. Quercetin caused no significant reduction in body weight
\end{abstract}

N. Arias - M. T. Macarulla - L. Aguirre .

M. G. Martínez-Castaño - M. P. Portillo

Nutrition and Obesity Group, Department of Nutrition and Food

Science, Faculty of Pharmacy, Lascaray Research Center,

University of the Basque Country (UPV/EHU), Vitoria, Spain

N. Arias · M. T. Macarulla - L. Aguirre - M. P. Portillo CIBERobn Physiopathology of Obesity and Nutrition, Institute of Health, Carlos III (ISCIII), Vitoria, Spain

M. G. Martínez-Castaño

Clinic Laboratory, University Hospital of Alava, Vitoria, Spain

M. P. Portillo $(\bowtie)$

Nutrición y Bromatología, Facultad de Farmacia, Universidad del País Vasco, Paseo de la Universidad 7, 01006 Vitoria, Spain e-mail: mariapuy.portillo@ehu.es or adipose tissue sizes. However, fructosamine, basal glucose and insulin, and consequently HOMA-IR, were significantly reduced by quercetin. No changes were observed in the activity of lipogenic enzymes and lipoprotein lipase. Muscle triacylglycerol content was similar in both experimental groups. The expression of ACO, CD36, CPT-1b, PPAR- $\alpha$, PGC- $1 \alpha, \mathrm{UCP}_{3}$, TFAM and COX-2 remained unchanged. It can be concluded that quercetin is more effective as an anti-diabetic than as an anti-obesity biomolecule. The improvement in insulin resistance induced by this flavonoid is not mediated by a delipidating effect in skeletal muscle.

Keywords Quercetin · Glycemic control · Fat accumulation - Adipose tissue - Muscle · Fatty acid oxidation $\cdot$ Rat

\section{Introduction}

Obesity is a major health problem in the industrialized world, which has reached epidemic proportions globally. Its high prevalence is a result of changes in lifestyle, decreased physical activity and socioeconomic development, among other factors. Moreover, obesity is a complex multi-factorial, chronic disease, which is considered to be a risk factor for the genesis or development of various diseases which include hypertension, type 2 diabetes, coronary heart disease and respiratory complications (Barness 2007; Kopelman 2000). In this context, scientific research is constantly seeking to identify for new molecules that could be used as dietary functional ingredients in the fight against this disease and its co-morbidities. Among them, flavonoids represent a group of molecules of increasing interest. 
Flavonoids belong to a group of natural substances, which have a variable phenolic structure and are found in fruit, vegetables, tea and wine. These natural foods were known for their beneficial effects on health long before flavonoids were isolated as the effective compounds. Flavonoids have a basic chemical structure of diphenylpropanes (C6-C3-C6) and are most often found attached to sugar (glycosides), but they can also be aglycones. Quercetin, which is found in abundance in onions, broccoli, tomatoes, apples and berries, is the most abundant flavonoid (Somerset and Johannot 2008).

It has been reported that quercetin exhibits a wide range of biological functions, including antioxidant, anticarcinogenic and anti-inflammatory activities (Bischoff 2008; Zhang et al. 2011; Chirumbolo 2010; Jung et al. 2013). More recently, beneficial effects on blood pressure and heart disease have been described (Perez-Vizcaino et al. 2009; Han et al. 2009; Jung et al. 2013). With regard to obesity, very little work has been carried out to date. As far as glycemic control is concerned, quercetin has been reported to improve diabetic status in animal models of either type 1 or type 2 diabetes (Aguirre et al. 2011).

The first aim of the present work was to gain more insight into the effects of quercetin on fat accumulation in adipose tissue and on glycemic control in rats fed an obesogenic diet, in order to establish whether this molecule can be useful in the prevention of obesity and insulin resistance related to it. A second aim was to determine the potential involvement of muscle fatty acid oxidation in the effect of quercetin on glycemic control.

\section{Materials and methods}

Diets and experimental design for the in vivo study

The study was conducted with eighteen 6-week-old male Wistar rats purchased from Harlan Ibérica (Barcelona, Spain), and took place in accordance with the institution's guide for the care and use of laboratory animals (CUEID CEBA/30/2010).

Rats were individually housed in polycarbonate metabolic cages (Techniplast Gazzada, Guguggiate, Italy) and placed in an air-conditioned room $\left(22 \pm 2{ }^{\circ} \mathrm{C}\right)$ with a 12-h day-night rhythm. After a 6-day adaptation period, rats were randomly distributed in two groups $(n=9$ per group): a control group and a quercetin group. Both groups were fed a commercial high-fat, high-sucrose diet (Harlan Ibérica; ref. TD. 06415) for 6 weeks. This diet was high in fat $(225 \mathrm{~g} / \mathrm{kg})$ and sucrose $(200 \mathrm{~g} / \mathrm{kg})$ and was either supplemented with quercetin (Sigma-Aldrich, St. Louis, MO, USA) or not supplemented. For dietary supplementation, quercetin was added to the diet daily in amounts that assured a dose of $30 \mathrm{mg} / \mathrm{kg}$ body weight/d (equivalent approximately to $0.045 \%$ of quercetin in the diet). All animals had free access to food and water. Body weight and food intake were recorded on a daily basis.

At the end of the experimental period, animals were exsanguinated by cardiac puncture under anesthesia (chloral hydrate). Adipose tissue from different anatomical locations (epididymal, perirenal, mesenteric and subcutaneous) and gastrocnemius muscles were dissected, weighted, immediately frozen and stored at $-80{ }^{\circ} \mathrm{C}$ for further analysis.

\section{Glucose tolerance test}

One week before killing, all rats were deprived of food, though not of water, $12 \mathrm{~h}$ before starting the experiment. Blood samples were obtained from the tail vein for the determination of basal glucose and insulin levels. Glucose load was injected intraperitoneally at the dose of $2 \mathrm{~g} / \mathrm{kg}$ body weight, and glycemia was determined from the tail vein after 30, 60, 90 and $120 \mathrm{~min}$. The area under the curve (AUC) was calculated by trapezoidal method (Tai 1994).

\section{Serum analysis}

Serum was obtained from blood samples after centrifugation $\left(1,000 \mathrm{~g}\right.$ for $10 \mathrm{~min}$ at $\left.4{ }^{\circ} \mathrm{C}\right)$. Commercial kits were employed to measure serum parameters: glucose (BioSystems, Barcelona, Spain), insulin (Linco, St. Charles, MO, USA), fructosamine (Spinreact, Sant Esteve de Bas, Spain) and free fatty acids (Roche, Penzberg, Germany).

The homeostatic model assessment for insulin resistance (HOMA-IR) was calculated from basal insulin and glucose values using Matthews' formula (Matthews et al. 1985):

$$
\begin{aligned}
\text { HOMA-IR }= & {[\text { Fasting glucose }(\mathrm{mmol} / \mathrm{L})} \\
& \times \text { fasting insulin }(\mathrm{mU} / \mathrm{L})] / 22.5
\end{aligned}
$$

Lipoprotein lipase and lipogenic activities in white adipose tissue

For heparin-releasable lipoprotein lipase (HR-LPL) activity determination, $400 \mathrm{mg}$ of epididymal adipose tissue was incubated in $400 \mu \mathrm{L}$ of KRP (Krebs-Ringer Phosphate) buffer, containing $2 \mu \mathrm{g} / \mathrm{mL}$ of heparine, at $37{ }^{\circ} \mathrm{C}$ during $45 \mathrm{~min}$. Aliquots of this medium were incubated for $5 \mathrm{~min}$ at $37{ }^{\circ} \mathrm{C}$ with $1 \mathrm{mg}$ dibutyryl fluorescein, $5 \mathrm{~mL}$ ethyleneglycol monoethyl ether, $3 \mathrm{mM} \mathrm{NaH}_{2} \mathrm{PO}_{4}$ and $50 \mathrm{mM}$ $\mathrm{Na}_{2} \mathrm{HPO}_{4}$ with $2.5 \mathrm{M} \mathrm{NaCl}$, or not, and then, the reaction was stopped in ice. Finally, fluorescence was measured. HR-LPL activity was calculated by subtracting non-LPL lipolytic activity in the presence of $\mathrm{NaCl}$ from the total lipolytic activity, determined without $\mathrm{NaCl}$, and was 
expressed as nmol fluorescein released per minute per gram of tissue.

For lipogenic enzyme analysis purposes, $1 \mathrm{~g}$ of epididymal adipose tissue was homogenized in $3.0 \mathrm{~mL}$ of buffer (pH 7.6) containing $150 \mathrm{mM} \mathrm{KCl}, 1 \mathrm{mM} \mathrm{MgCl} 2,10 \mathrm{mM}$ $N$-acetyl-cysteine and $0.5 \mathrm{mM}$ dithiothreitol. After centrifugation at $100,000 \mathrm{~g}$ for $40 \mathrm{~min}$ at $4{ }^{\circ} \mathrm{C}$, the supernatant fraction was used for the quantification of enzyme activities. Fatty acid synthase (FAS), glucose-6-phosphate dehydrogenase (G6PDH) and malic enzyme (ME) activities were measured as previously described (Zabala et al. 2006). Enzyme activities were expressed as follows: nmol NADPH consumed per minute per $g$ of tissue for FAS, and nmol NADPH produced per minute per $g$ of tissue for G6PDH and ME.

Acetyl CoA carboxylase (ACC) activity was measured by using the ratio phosphorylated ACC/total ACC. The amounts of both ACC-phosphorylated and total ACC were measured by Western blot. To this end, $100 \mathrm{mg}$ of epididymal adipose tissue was homogenated in $500 \mu \mathrm{L}$ of cellular PBS ( $\mathrm{pH}$ 7.4), containing nuclease inhibitors, $100 \mathrm{mM}$ phenylmethylsulfonyl fluoride and $100 \mathrm{mM}$ iodoacetamide. Homogenates were centrifuged at $500 \mathrm{~g}$ for $10 \mathrm{~min}$ at $4{ }^{\circ} \mathrm{C}$. Protein concentrations in homogenates were measured by using Bradford method (Bradford 1976) using bovine serum albumin as standard.

Immunoblot analyses were performed using $10 \mu \mathrm{g}$ epididymal adipose tissue extracts separated by electrophoresis in a $10 \%$ SDS-polyacrylamide gel and transferred to PVDF membranes. The membranes were then blocked with $5 \%$ caseine PBS-Tween buffer for $2 \mathrm{~h}$ at room temperature. Subsequently, they were blotted with the appropriate antibodies overnight at $4{ }^{\circ} \mathrm{C}$. ACC levels were detected via specific antibodies for total ACC $(1: 1,000)$, phosphorylated ACC (1:1,000) (Cell Signaling Technology, Danvers, MA, USA) and $\beta$-actin $(1: 5,000)$ (Sigma, St. Louis, MO, USA). Afterward, polyclonal mouse anti- $\beta$-actin and rabbit antiACC antibody (1:5,000) (Sigma, St. Louis, MO, USA) were incubated for $2 \mathrm{~h}$ at room temperature. First, total ACC was measured, and then phosphorylated ACC was determined by stripping and reprobing the blot. The bound antibodies were visualized by an ECL system (Thermo Fisher Scientific Inc., Rockford, IL, USA) and quantified by a ChemiDoc MP imaging system (Biorad, Hercules, Ca, USA). $\beta$-Actin was used as a loading control to normalize the results.

Triacylglycerols content in skeletal muscle

Total lipids were extracted from muscle samples according to Folch method (Folch et al. 1957). Lipid extract was dissolved in isopropanol. Triacylglycerol content was measured using a commercial kit (Spinreact, Sant Esteve de Bas, Spain).
Carnitine palmitoyltransferase-1b activity in skeletal muscle

The activity of carnitine palmitoyltransferase-1b (CPT-1b) was assessed in the mitochondrial/peroxisomal fraction. Tissue samples $(1.5 \mathrm{~g})$ were homogenized in $4.5 \mathrm{ml}$ of buffer $\mathrm{pH} 7.4$ containing $0.25 \mathrm{~mol} / \mathrm{L}$ sucrose, $1 \mathrm{mmol} / \mathrm{L}$ EDTA and $10 \mathrm{mmol} / \mathrm{L}$ Tris-HCl. Homogenates were centrifuged $\left(700 \mathrm{~g}\right.$ for $10 \mathrm{~min}$ at $4{ }^{\circ} \mathrm{C}$ ), and the supernatant fluid was again centrifuged $\left(12,000 \mathrm{~g}\right.$ for $15 \mathrm{~min}$ at $\left.4{ }^{\circ} \mathrm{C}\right)$. Pellets were resuspended in $70 \mathrm{mmol} / \mathrm{L}$ sucrose, $220 \mathrm{mmol} / \mathrm{L}$ mannitol, $1 \mathrm{mmol} / \mathrm{L}$ EDTA, $2 \mathrm{mmol} / \mathrm{L}$ HEPES buffer, $\mathrm{pH}$ 7.4. CPT-1b activity was assayed by using the Bieber method (Bieber et al. 1972). The pellet protein content was determined by the Bradford method (Bradford 1976). CPT-1b activity was expressed as nmol CoA formed per minute per mg protein.

Citrate synthase activity in skeletal muscle

Citrate synthase (CS) activity was determined spectrophotometrically following the Srere method (Srere 1969), by measuring the appearance of free CoA. Briefly, muscle samples were homogenated in $10 \mathrm{vol}(\mathrm{wt} / \mathrm{vol})$ of $0.1 \mathrm{M}$ Tris- $\mathrm{HCl}$ buffer ( $\mathrm{pH} 8.0$ ), and diluted by a factor of 200 in this buffer. Homogenates were incubated for $5 \mathrm{~min}$ at $30{ }^{\circ} \mathrm{C}$ with $0.1 \mathrm{M}$ Tris- $\mathrm{HCl}$ buffer containing $0.1 \mathrm{mM}$ DTNB, $0.25 \%$ Triton X-100, $0.5 \mathrm{mM}$ oxaloacetate and $0.31 \mathrm{mM}$ acetyl CoA, and readings were taken at $412 \mathrm{~nm}$. $\mathrm{CS}$ activity was expressed as nmol CoA formed per minute per mg of protein.

Extraction and analysis of RNA and semiquantification by reverse transcription-polymerase chain reaction (RT-PCR)

Total RNA was isolated from $100 \mathrm{mg}$ of muscle using Trizol (Invitrogen, Carlsbad, CA, USA), according to the manufacturer's instructions. RNA samples were then treated with DNA-free kit (Applied Biosystems, Austin, TX, USA) to remove any contamination with genomic DNA. The yield and quality of the RNA were assessed by measuring absorbance at 260, 270, 280 and $310 \mathrm{~nm}$. A total of $1.5 \mu \mathrm{g}$ of total RNA of each sample was reverse-transcribed to first-strand complementary DNA (cDNA) using iScript ${ }^{\mathrm{TM}}$ cDNA Synthesis Kit (Bio-Rad, Hercules, CA, USA). Acyl-coenzyme A oxidase (ACO), carnitine palmitoyl transferase-1b (CPT-1b), peroxisome proliferator-activated receptor gamma coactivator 1- $\alpha$ (PGC-1 $\alpha$ ), peroxisome proliferator-activated receptor $\alpha$ (PPAR- $\alpha$ ), cluster of differentiation 36 (CD36), transcription factor A; mitochondrial (TFAM), cyclooxygenase-2 $(\mathrm{COX}-2)$, and uncoupling protein $3\left(\mathrm{UCP}_{3}\right)$ genes were quantified, as well as $18 \mathrm{~S}$ which served as the reference gene. 
Table 1 Primers for PCR amplification of each gene studied

\begin{tabular}{|c|c|c|}
\hline Primers & Sense primer & Antisense primer \\
\hline $\mathrm{CO}$ & $\begin{array}{l}5^{\prime} \text {-TC TCT GTG GTT } \\
\text { GCT GTG GAG TCA-3' }\end{array}$ & $\begin{array}{l}5^{\prime} \text {-TC GGA TGC TTC CTT } \\
\text { CTC CAA GGT-3' }\end{array}$ \\
\hline $\begin{array}{l}\text { CPT- } \\
1 \mathrm{~b}\end{array}$ & $\begin{array}{l}\text { 5'-CAA ACA TCA CTG }^{\text {CCC AAG CTT- } 3^{\prime}}\end{array}$ & $\begin{array}{l}5^{\prime} \text {-GGC CGC ACA GAA } \\
\text { TCC AAG T-3' }\end{array}$ \\
\hline $\begin{array}{l}\text { PGC- } \\
1 \alpha\end{array}$ & $\begin{array}{l}5^{\prime}-\mathrm{CA} \text { AAG CTG AAG } \\
\text { CCC TCT TGC-3' }\end{array}$ & $\begin{array}{l}5^{\prime} \text {-GTT TAG TCT TCC TTT } \\
\text { CCT CGT GTC C-3' }\end{array}$ \\
\hline $\begin{array}{l}\text { PPAR- } \\
\alpha\end{array}$ & $\begin{array}{l}5^{\prime} \text {-GCT ACT TCG AGT } \\
\text { CCC CTT GAG-3' }\end{array}$ & $\begin{array}{l}5^{\prime} \text {-CCA GCG TCG CTT } \\
\text { CAG TTC C-3' }\end{array}$ \\
\hline CD36 & $\begin{array}{l}5^{\prime} \text {-GGT GTG CTC AAC } \\
\text { AGC CTT ATC-3' }\end{array}$ & $\begin{array}{l}5^{\prime} \text {-TTA TGG CAA CCT } \\
\text { TGC TTA TG-3' }\end{array}$ \\
\hline TFAM & $\begin{array}{l}5^{\prime} \text {-CAC GAG CCC TGG } \\
\text { AGT ACC C-3' }\end{array}$ & 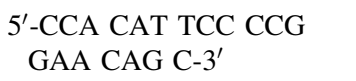 \\
\hline $\mathrm{COX}-2$ & $\begin{array}{r}5^{\prime} \text {-AAC AAT TCT CCC } \\
\text { AGC TGT CAT TC-3' }\end{array}$ & $\begin{array}{l}\text { 5'-AGT CAA AGC ATA } \\
\text { GGT CTT CAT AGT C-3 }\end{array}$ \\
\hline $\mathrm{UCP}_{3}$ & $\begin{array}{c}5^{\prime} \text {-TAC ACC TCC TGA } \\
\text { CCT TGG CTA G-3' }\end{array}$ & $\begin{array}{l}5^{\prime} \text {-CTG TTG TGG GAG } \\
\text { GCA CTT CTG-3' }\end{array}$ \\
\hline $18 \mathrm{~S}$ & $\begin{array}{l}5^{\prime} \text {-GTG GGC CTG CGG } \\
\text { CTT AAT- } 3^{\prime}\end{array}$ & $\begin{array}{l}5^{\prime} \text {-GCC AGA GTC TCG } \\
\text { TTC GTT ATC- } 3^{\prime}\end{array}$ \\
\hline
\end{tabular}

$A C O$ acyl-coenzyme A oxidase, $C P T-1 b$ carnitine palmitoyl transferase-1b, $P G C$ - $1 \alpha$ peroxisome proliferator-activated receptor gamma coactivator $1-\alpha, P P A R-\alpha$ peroxisome proliferator-activated receptor $\alpha$; CD36 cluster of differentiation 36, TFAM transcription factor A; mitochondrial; $C O X-2$ cyclooxygenase-2, $U C P_{3}$ uncoupling protein 3

A 9.5- $\mu \mathrm{L}$ aliquot of each diluted cDNA sample was used for polymerase chain reaction amplification in a $25-\mu \mathrm{L}$ reaction volume. The cDNA samples were amplified on an iCycler-MyiQ Real Time PCR Detection System (Bio-Rad, Hercules, CA, USA) in the presence of SYBRGreen master mix (Applied Biosystems, Austin, TX, USA) and a $300 \mathrm{nM}$ concentration of each of the sense and antisense primers. Specific primers were synthesized commercially (Integrated DNA Technologies, Leuven Belgium), and the sequences are as described in Table 1. The PCR parameters were as follows: initial $2 \mathrm{~min}$ at $50{ }^{\circ} \mathrm{C}$, denaturation at $95^{\circ} \mathrm{C}$ for 10 min followed by 40 cycles of denaturation at $95^{\circ} \mathrm{C}$ for $15 \mathrm{~s}$, annealing at $60{ }^{\circ} \mathrm{C}$ for $30 \mathrm{~s}$ and extension at $60^{\circ} \mathrm{C}$ for $30 \mathrm{~s}$. In the case of PGC- $1 \alpha$ and $\mathrm{CD} 36$, the annealing temperature was $63.9{ }^{\circ} \mathrm{C}$ and $66.4{ }^{\circ} \mathrm{C}$, respectively.

Gene expression analysis was performed using the comparative threshold cycle $(\mathrm{Ct})$ method. Amplification of $18 \mathrm{~S}$ sequence was performed in parallel and was used to normalize values obtained for target genes. The results were expressed as fold changes of threshold cycle $(\mathrm{Ct})$ value relative to controls using the $2^{-\Delta \Delta \mathrm{Ct}}$ method (Livak and Schmittgen 2001).

\section{Statistical analysis}

Results are presented as mean \pm SEM. Statistical analysis was performed using SPSS 17.0 (SPSS, Chicago, IL, USA). Normal distribution of data was confirmed by Shapiro-
Table 2 Serum parameters of rats from control and quercetin-treated groups

\begin{tabular}{lccl}
\hline & Control & Quercetin & $P$ \\
\hline Glucose $(\mathrm{mmol} / \mathrm{L})$ & $5.53 \pm 0.40$ & $4.09 \pm 0.16$ & $<0.01$ \\
Insulin $(\mathrm{mU} / \mathrm{L})$ & $37 \pm 7$ & $12 \pm 2$ & $<0.01$ \\
HOMA-IR & $9.5 \pm 1.9$ & $2.2 \pm 0.3$ & $<0.01$ \\
Fructosamine $(\mu \mathrm{mol} / \mathrm{L})$ & $346 \pm 12$ & $279 \pm 6$ & $<0.01$ \\
Free fatty acids $(\mu \mathrm{mol} / \mathrm{L})$ & $1.20 \pm 0.19$ & $1.45 \pm 0.26$ & $\mathrm{NS}$ \\
\hline
\end{tabular}

$N S$ not significant

Values are mean \pm SEM ( $n=9$ per group). Differences between groups were determined using Student's $t$ test. Statistical significance was set at the $P<0.05$ level

Wilks test. Therefore, data were analyzed by Student's $t$ test. Significance was assessed at the $P<0.05$ level.

\section{Results}

Food intake, food efficiency, body weight and tissue weights

No significant differences were found between experimental groups in terms of food intake $(\mathrm{g} / \mathrm{d})(17.4 \pm 0.4$ in the control group vs. $16.7 \pm 0.3$ in the quercetin-treated group), or of final body weight ( $\mathrm{g}$ ) (393 \pm 8 in the control group vs. $385 \pm 3$ and in the quercetin-treated group). Consequently, food efficiency calculated as increment of body weight/food intake remained unchanged $(\mathrm{g} / \mathrm{g})$ $(0.28 \pm 0.01$ in the control group vs. $0.27 \pm 0.01$ in the quercetin-treated group).

With regard to fat accumulation in adipose tissue, the sum of epididymal, perirenal, mesenteric and subcutaneous adipose depots represented a $9.1 \%$ reduction in the quercetin-treated group $(55.8 \pm 2.8 \mathrm{~g}$ in the control group vs. $50.7 \pm 1.5 \mathrm{~g}$ in the quercetin-treated group), although this difference did not reach statistical significance. Moreover, no significant differences were found in gastrocnemius muscle weights $(\mathrm{g})(2.56 \pm 0.13$ in the control group vs. $2.43 \pm 0.10$ in the quercetin-treated group).

Serum parameters and glucose tolerance test

Basal glucose and insulin were significantly reduced $(P<0.01)$ by quercetin. Consequently, HOMA-IR, an indirect index of insulin resistance, was also diminished $(P<0.01)$. Moreover, fructosamine concentration (an indicator of the average blood glucose concentration over a short-medium period) was significantly reduced by the addition of quercetin to the diet $(P<0.01)$. However, no significant differences were found in free fatty acid concentrations (Table 2). 
Fig. 1 Glycemic response in glucose tolerance test (a) and area under the curve (AUC) of glucose tolerance test (b) of rats from Control and Quercetintreated groups $(n=9$ per group). Values are mean \pm SEM. Differences between groups were determined by Student's $t$ test. Statistical significance was set at the $P<0.05$ level. $* P<0.05$
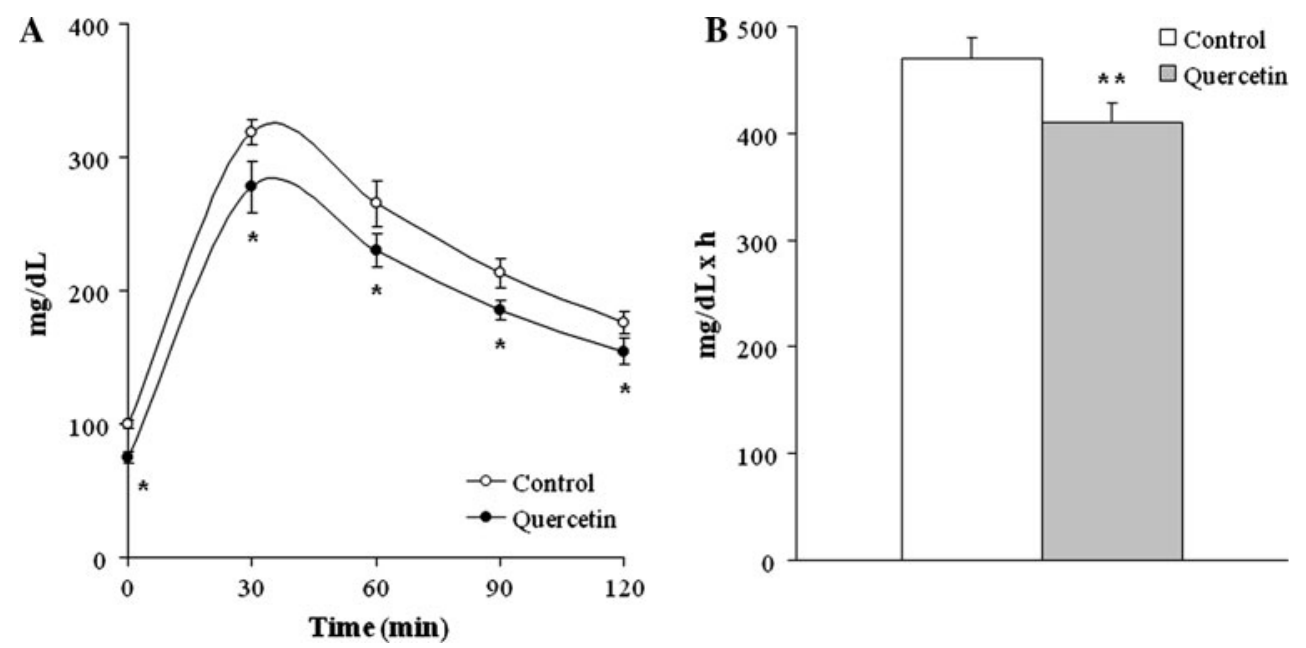

Table 3 Enzyme activities in adipose tissue and skeletal muscle of rats from control and quercetin-treated groups

\begin{tabular}{lcrc}
\hline & Control & Quercetin & $P$ \\
\hline Adipose tissue & & & \\
G6PDH (nmol/min/g tissue) & $84.5 \pm 18.0$ & $62.6 \pm 9.9$ & NS \\
ME (nmol/min/g tissue) & $55.6 \pm 5.7$ & $56.9 \pm 6.3$ & NS \\
FAS (nmol/min/g tissue) & $12.1 \pm 1.2$ & $10.5 \pm 1.5$ & NS \\
HR-LPL (nmol/min/g tissue) & $7.0 \pm 0.9$ & $8.4 \pm 0.9$ & NS \\
Skeletal muscle & & & \\
CPT-1b (nmol/min/mg protein) & $3.7 \pm 1.0$ & $4.7 \pm 1.4$ & NS \\
CS (nmol/min/mg protein) & $34.6 \pm 5.4$ & $42.7 \pm 5.5$ & NS \\
\hline
\end{tabular}

Values are mean \pm SEM ( $n=9$ per group). Differences between groups were determined by Student's $t$ test. Statistical significance was set at the $P<0.05$ level

G6PDH glucose-6-phosphate dehydrogenase, $M E$ malic enzyme, FAS fatty acid synthase, $H R-L P L$ heparin-releasable lipoprotein lipase, $C P T-1 b$ carnitine palmitoyl transferase- $1 \mathrm{~b}, C S$ citrate synthase, $N S$ not significant

In the glucose tolerance test, rats treated with quercetin showed significantly lower blood glucose values than control rats. Consequently, AUC in quercetin group was significantly reduced $(-13 \%, P<0.01)$ (Fig. 1a, b).

Enzyme activities in adipose tissue

Quercetin treatment did not modify the activity of lipogenic enzymes (G6PDH, ME and FAS) and HR-LPL in adipose tissue (Table 3). The phosphorylated ACC/total ACC protein ratio remained unchanged $(2.37 \pm 0.41$ in the control group vs. $1.55 \pm 0.41$ in the quercetin-treated group), indicating that ACC activity was not modified by quercetin.

Skeletal muscle determinations

No significant differences were found in triacylglycerol content $(\mathrm{mg} / \mathrm{g})(11.3 \pm 1.8$ in the control group vs.
$8.6 \pm 0.8$ in the quercetin-treated group). The amount of this lipid species in skeletal muscle depends to a great extent on fatty acid oxidation. Thus, the gene expression (Fig. 2) and the activity of CPT-1b, a rate-limiting enzyme for this metabolic pathway, and citrate synthase activity, a marker of mitochondrial density (Pajuelo et al. 2011), were assessed, and no significant differences were found between groups (Table 3).

Skeletal muscle was also used to measure the expression of CD36, a fatty acid transporter, as well of that of genes related to fatty acid oxidation, such as CPT-1b, ACO, PPAR- $\alpha$, PGC- $1 \alpha$ and $\mathrm{UCP}_{3}$. Finally, the expression of genes known as markers of mitochondria number, such as TFAM and COX-2, was analyzed. No effect on the expression of all these genes was observed (Fig. 2).

\section{Discussion}

Evidence supporting the health benefits of polyphenols has been increasing over the course of the past few years. In the field of obesity and related metabolic alterations, some of these polyphenols have shown a clear anti-obesity action in animal models. One of the most frequently studied molecules is resveratrol, which belongs to the group of stilbenes (Ahn et al. 2008a; Baile et al. 2011; Baur et al. 2006; DalPan et al. 2010; Macarulla et al. 2009; Rivera et al. 2009; Szkudelska et al. 2009). With regard to flavonoids, and more specifically to quercetin, little is known of any potential role in obesity prevention or treatment.

In vitro studies have demonstrated that quercetin reduces triacylglycerol accumulation in cultured adipocytes (Kuppusamy and Das 1992; Hsu and Yen 2006; Ahn et al. 2008b). Data obtained in these studies are interesting and promising, but it is essential not to forget that important limitations exist in extrapolating these results to the in vivo situation. With regard to in vivo studies, some of these 


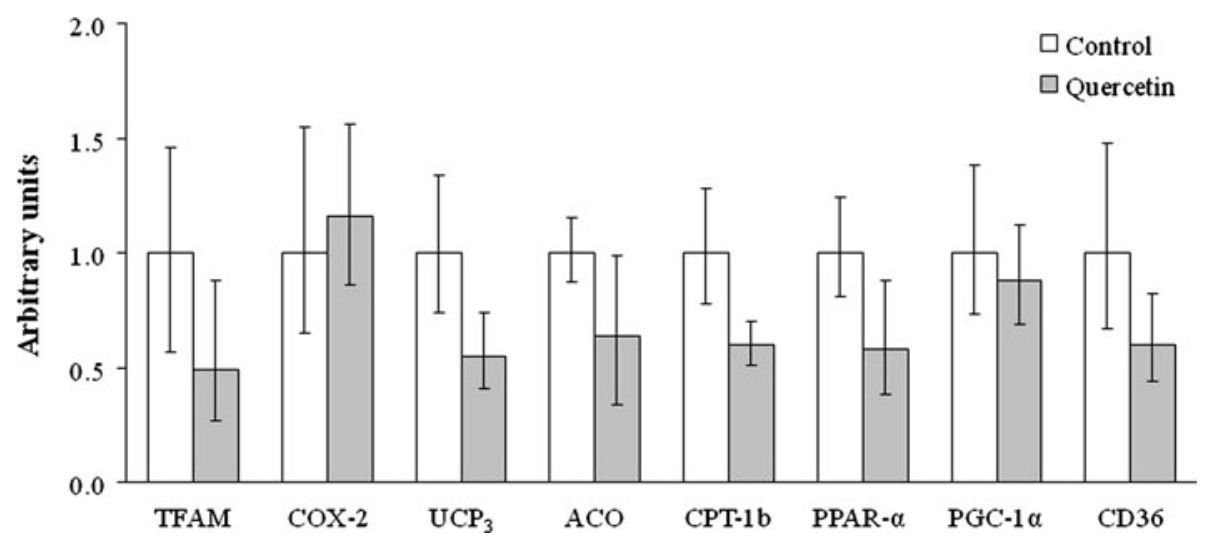

Fig. 2 Gene expressions in skeletal muscle of rats from Control and Quercetin-treated groups ( $n=9$ per group). Results are expressed as fold changes of threshold cycle $(\mathrm{Ct})$ value relative to controls. Values are means \pm positive and negative errors. Differences between groups were determined by Student's $t$ test. Statistical significance was set at the $P<0.05$ level. No significant difference was found

analyzed the effect of quercetin on body weight although body fat was not measured (Rivera et al. 2008; Kim et al. 2011). A small number of studies have analyzed the effect of this flavonoid on body fat. Stewart et al. (2008) found no changes in adiposity among mice fed on a high-fat diet supplemented with $0.8 \%$ of quercetin (which led to a dose of approximately $30 \mathrm{mg} / \mathrm{kg}$ body weight/day) for 3 or 8 weeks. By contrast, Kobori et al. (2011) observed a significant decrease in visceral fat $(-15.5 \%)$ in mice fed a Western diet supplemented with $0.5 \%$ quercetin for 20 weeks. More recently, Jung et al. (2013) have found a significant reduction in epididymal adipose tissue in mice fed a diet supplemented with $0.025 \%$ for 9 weeks. With regard to experiments performed in rats, no changes in adipose tissue weight were observed in animals fed a highfat diet supplemented with $0.03 \%$ (25 mg diet $/ \mathrm{kg}$ of body weight/day) for 4 weeks (Wein et al. 2010). By contrast, quercetin attenuated abdominal obesity $(-37 \%)$ in animals fed on a high-fat diet supplemented with $0.08 \%$ quercetin for 8 weeks (Panchal et al. 2012).

As indicated in the previous paragraph, reported data from studies carried out in mice have been obtained by using a wide range of quercetin doses $(0.025-0.8 \%$ in the diet). Significant reductions in body fat have been observed in this range even with the lowest dose of $0.025 \%$. This suggests that high doses are not needed for this flavonoid to show anti-obesity effects. Another important factor to be considered is the length of the treatment period needed to cause a significant effect. Among the reported studies, those with experimental periods of 9 and 20 weeks reported significant reductions in body fat, and those with shorter experimental periods (3-8 weeks) did not. Thus, it can be hypothesized that quercetin may need at least 9 weeks to be effective as an anti-obesity molecule in mice. When data between both experimental groups. TFAM transcription factor A; mitochondrial; $C O X-2$ cyclooxygenase-2; $U_{C P}$ uncoupling protein 3; $A C O$ acyl-coenzyme A oxidase; $C P T-1 b$ carnitine palmitoyl transferase-1b;PPAR- $\alpha$ peroxisome proliferator-activated receptor $\alpha$; $P G C-1 \alpha$ peroxisome proliferator-activated receptor gamma coactivator $1-\alpha ; C D 36$ cluster of differentiation 36

obtained in rats are analyzed, it can be observed that a dose of $0.3 \%$ was effective in mice while ineffective in rats (Wein et al. 2010). This can support the hypothesis that short experimental periods are not enough for quercetin to reduce body fat because in that study, rats were treated for 4 weeks. Nevertheless, the possibility of a varying speciesdependent threshold dose cannot be discarded.

In the present study, quercetin reduced by $9.1 \%$ the fat accumulated in the four fat pads dissected and weighed (epididymal + perirenal + mesenteric + subcutaneous $)$, but this reduction did not reach statistical significance. Taking into account the hypothesis provided in the previous paragraph, based on the results reported in the literature, the lack of a significant change could be attributable to the length of the experimental period. In this context, it is important to point out that in previous studies from this laboratory using exactly the same experimental design as the present study (polyphenol dose, treatment period length, diet, animals model), resveratrol induced a significant reduction in adipose tissue sizes (Alberdi et al. 2011), indicating that important differences exist in the potential anti-obesity action of polyphenols.

In order to gain more insight into the effect of quercetin on adipose tissue triacylglycerol metabolism, the activities of lipogenic enzymes (G6PDH, ME, FAS, ACC) and HRLPL were analyzed. No changes were observed in any enzyme activity, which indicates that neither de novo lipogenesis nor the lipid uptake from circulating lipoproteins was affected by this flavonoid.

Taken together, these data do not lend support to an antiobesity action of quercetin under the experimental conditions of dose and over the experimental period described here. When considering this conclusion, it is important to underline that the dose used in the present study 
(30 $\mathrm{mg} / \mathrm{kg} /$ day), which is very similar to those used in other studies carried out in rodents, was equivalent to $4.86 \mathrm{mg} / \mathrm{kg}$ body weight/day in humans (340.5 mg for a person of $70 \mathrm{~kg}$ ), calculated by using the formula reported by Reagan-Shaw et al. (2008), which is in the 200-400 mg/ day range of average human consumption (Manach et al. 1998).

It is well known that a high-fat high-sucrose diet leads not only to increased body fat accumulation, but also to insulin resistance (Hegarty et al. 2003). In the present study, quercetin improved glycemic control, as shown by the HOMA-IR index, which in rats yields a good estimate of whole body insulin sensitivity (Cacho et al. 2008), glucose tolerance test and serum fructosamine concentration. This would appear to be a direct effect, independent of the fat accumulated in adipose tissues, since a significant reduction in this parameter was not observed. On the other hand, as previously mentioned, data in the literature suggest that treatment periods of $<9$-week duration are insufficient for quercetin to reduce fat but, according to the results showed in the present study, they allow this flavonoid to improve insulin action. This lends support to the hypothesis that the effect of quercetin on insulin action is independent of, and previous to, the effect on fat accumulation.

The present results are in good accordance with other published studies carried out in animal models showing insulin resistance or type 2 diabetes (Wein et al. 2010; Rivera et al. 2008; Kim et al. 2011; Jeong et al. 2012). Nevertheless, there is no general agreement concerning the effect of quercetin on glycemic control. For example, Stewart et al. (2008), whose experiment induced insulin resistance in rats by feeding animals on a high-fat diet, observed that quercetin, at a dose of $0.8 \%$ in the diet, exacerbated diet-induced insulin resistance at 3 weeks.

The authors of those studies which found positive effects of quercetin on glycemic control proposed several mechanisms to explain the beneficial effect of this polyphenol: (a) the anti-oxidative protective action on the pancreatic islets (Coskun et al. 2005; Babujanarthanam et al. 2010; Jeong et al. 2012), (b) the increase in adiponectin circulating concentration (Wein et al. 2010), (c) the inhibition of small intestine glucosidase activity (Kim et al. 2011), (d) the reduction in the intestinal glucose absorption mediated by GLUT2 (Kwon et al. 2007), (e) the increase in glucokinase activity (Vessal et al. 2003) and (f) the increase in GLUT4 transporters in skeletal muscle (Jung et al. 2011; Shen et al. 2012; Anhê et al. 2012).

Recently, Shen et al. (2012) have proposed a new mechanism to explain the improvement in insulin resistance induced by pentamethylquercetin. These authors have shown that this flavonoid increases the expression of genes involved in fatty acid oxidation, such as PPAR- $\alpha$, PGC- $1 \alpha, \mathrm{CPT}-1 \mathrm{~b}$ and $\mathrm{ACO}$, in $\mathrm{C} 2 \mathrm{C} 12$ myotubes.
Skeletal muscle, the major peripheral tissue in which insulin-responsive glucose uptake and utilization take place, is one of the tissues negatively affected by insulin resistance. One of the proposed factors involved in the impairment of insulin function is increased skeletal muscle lipid deposition (Hulver and Dohm 2004). Under overfeeding conditions which lead to obesity, such as those of the present study, the influx of fatty acids to skeletal muscle is increased. This causes increased intramyocellular concentration of triacylglycerols and leads to insulin resistance by perturbing insulin signaling pathways (Eckardt et al. 2011).

The mechanism of action proposed by Shen et al. (2012) has not been demonstrated under in vivo conditions. Thus, in this context, the potential involvement of increased fatty acid oxidation in skeletal muscle in the reduction in insulin resistance induced by quercetin was assessed in the present study. Quercetin did not modify the expression of genes related to fatty acid oxidation, such as the transcription factor PPAR- $\alpha$, its co-activator PGC- $1 \alpha$ and two key enzymes CPT-1b and ACO regulated by PPAR- $\alpha$. A similar situation was found when the expression of genes considered as markers of mitochondria number, such as TFAM and COX-2, was assessed. Finally, the expression $\mathrm{UCP}_{3}$, an uncoupling protein related to fatty acid oxidation (Senese et al. 2011) and CD36, a fatty acid transporter, remained unchanged after quercetin treatment. In good accordance with these data, quercetin did not modify the activity of CPT-1b and CS, a marker of mitochondrial density (Pajuelo et al. 2011), and did not show a delipidating effect in skeletal muscle. These results demonstrate that the increase in fatty acid oxidation reported under in vitro conditions in $\mathrm{C} 2 \mathrm{C} 12$ myotubes did not take place in an animal model of insulin resistance, at least under the experimental conditions described here.

In conclusion, the present results suggest that quercetin seems to be more effective as an anti-diabetic than as an anti-obesity biomolecule, and that the improvement in insulin resistance induced by this flavonoid is not mediated by a delipidating effect in skeletal muscle.

Acknowledgments This study was supported by Grants from the Ministerio de Economía y Competitividad (AGL2011-27406-ALI), Instituto de Salud Carlos III (CIBERobn), Government of the Basque Country (IT-512-13) and University of the Basque Country (UPV/ EHU) (ELDUNANOTEK, UFI11/32). N. Arias is a recipient of a doctoral fellowship from the Government of the Basque Country (UPV/EHU).

\section{References}

Aguirre L, Arias N, Macarulla MT, Gracia A, Portillo MP (2011) Beneficial effects of quercetin on obesity and diabetes. Open Nutraceuticals J 4:189-198 
Ahn J, Cho I, Kim S, Kwon D, Ha T (2008a) Dietary resveratrol alters lipid metabolism-related gene expression of mice on an atherogenic diet. J Hepatol 49(6):1019-1028

Ahn J, Lee H, Kim S, Park J, Ha T (2008b) The anti-obesity effect of quercetin is mediated by the AMPK and MAPK signaling pathways. Biochem Biophys Res Commun 373(4):545-549

Alberdi G, Rodríguez VM, Miranda J, Macarulla MT, Arias N, Andrés-Lacueva C, Portillo MP (2011) Changes in white adipose tissue metabolism induced by resveratrol in rats. Nutr Metab (Lond) 8(1):29

Anhê GF, Okamoto MM, Kinote A, Sollon C, Lellis-Santos C, Anhê FF, Lima GA, Hirabara SM, Velloso LA, Bordin S, Machado UF (2012) Quercetin decreases inflammatory response and increases insulin action in skeletal muscle of ob/ob mice and in L6 myotubes. Eur J Pharmacol 689(1-3):285-293

Babujanarthanam R, Kavitha P, Pandian MR (2010) Quercitrin, a bioflavonoid improves glucose homeostasis in streptozotocininduced diabetic tissues by altering glycolytic and gluconeogenic enzymes. Fundam Clin Pharmacol 24(3):357-364

Baile CA, Yang JY, Rayalam S, Hartzell DL, Lai CY, Andersen C, Della-Fera MA (2011) Effect of resveratrol on fat mobilization. Ann NY Acad Sci 1215:40-47

Barness LA (2007) Obesity in children. Fetal Pediatr Pathol 26(2):75-85

Baur JA, Pearson KJ, Price NL, Jamieson HA, Lerin C, Kalra A, Prabhu VV, Allard JS, Lopez-Lluch G, Lewis K, Pistell PJ, Poosala S, Becker KG, Boss O, Gwinn D, Wang M, Ramaswamy S, Fishbein KW, Spencer RG, Lakatta EG, Le Couteur D, Shaw RJ, Navas P, Puigserver P, Ingram DK, de Cabo R, Sinclair DA (2006) Resveratrol improves health and survival of mice on a high-calorie diet. Nature 444(7117):337-342

Bieber LL, Abraham T, Helmrath T (1972) A rapid spectrophotometric assay for carnitine palmitoyltransferase. Anal Biochem 50(2):509-518

Bischoff SC (2008) Quercetin: potentials in the prevention and therapy of disease. Curr Opin Clin Nutr Metab Care 11(6): 733-740

Bradford MM (1976) A rapid and sensitive method for the quantitation of microgram quantities of protein utilizing the principle of protein-dye binding. Anal Biochem 72:248-254

Cacho J, Sevillano J, de Castro J, Herrera E, Ramos MP (2008) Validation of simple indexes to assess insulin sensitivity during pregnancy in Wistar and Sprague-Dawley rats. Am J Physiol Endocrinol Metab 295(5):E1269-E1276

Chirumbolo S (2010) The role of quercetin, flavonols and flavones in modulating inflammatory cell function. Inflamm Allergy Drug Targets 9(4):263-285

Coskun O, Kanter M, Korkmaz A, Oter S (2005) Quercetin, a flavonoid antioxidant, prevents and protects streptozotocininduced oxidative stress and beta-cell damage in rat pancreas. Pharmacol Res 51(2):117-123

Dal-Pan A, Blanc S, Aujard F (2010) Resveratrol suppresses body mass gain in a seasonal non-human primate model of obesity. BMC Physiol 10:11

Eckardt K, Taube A, Eckel J (2011) Obesity-associated insulin resistance in skeletal muscle: role of lipid accumulation and physical inactivity. Rev Endocr Metab Disord 12(3):163-172

Folch J, Lees M, Sloane Stanley GH (1957) A simple method for the isolation and purification of total lipides from animal tissues. J Biol Chem 226(1):497-509

Han JJ, Hao J, Kim CH, Hong JS, Ahn HY, Lee YS (2009) Quercetin prevents cardiac hypertrophy induced by pressure overload in rats. J Vet Med Sci 71(6):737-743

Hegarty BD, Furler SM, Ye J, Cooney GJ, Kraegen EW (2003) The role of intramuscular lipid in insulin resistance. Acta Physiol Scand 178(4):373-383
Hsu CL, Yen GC (2006) Induction of cell apoptosis in 3T3-L1 preadipocytes by flavonoids is associated with their antioxidant activity. Mol Nutr Food Res 50(11):1072-1079

Hulver MW, Dohm GL (2004) The molecular mechanism linking muscle fat accumulation to insulin resistance. Proc Nutr Soc 63(2):375-380

Jeong SM, Kang MJ, Choi HN, Kim JH, Kim JI (2012) Quercetin ameliorates hyperglycemia and dyslipidemia and improves antioxidant status in type 2 diabetic db/db mice. Nutr Res Pract 6(3):201-207

Jung JY, Lim Y, Moon MS, Kim JY, Kwon O (2011) Onion peel extracts ameliorate hyperglycemia and insulin resistance in high fat diet/streptozotocin-induced diabetic rats. Nutr Metab (Lond) $8(1): 18$

Jung CH, Cho I, Ahn J, Jeon TI, Ha TY (2013) Quercetin reduces high-fat diet-induced fat accumulation in the liver by regulating lipid metabolism genes. Phytother Res 27(1):139-143

Kim JH, Kang MJ, Choi HN, Jeong SM, Lee YM, Kim JI (2011) Quercetin attenuates fasting and postprandial hyperglycemia in animal models of diabetes mellitus. Nutr Res Pract 5(2):107-111

Kobori M, Masumoto S, Akimoto Y, Oike H (2011) Chronic dietary intake of quercetin alleviates hepatic fat accumulation associated with consumption of a Western-style diet in C57/BL6J mice. Mol Nutr Food Res 55(4):530-540

Kopelman PG (2000) Obesity as a medical problem. Nature 404(6778):635-643

Kuppusamy UR, Das NP (1992) Effects of flavonoids on cyclic AMP phosphodiesterase and lipid mobilization in rat adipocytes. Biochem Pharmacol 44(7):1307-1315

Kwon O, Eck P, Chen S, Corpe CP, Lee JH, Kruhlak M, Levine M (2007) Inhibition of the intestinal glucose transporter GLUT2 by flavonoids. FASEB J 21(2):366-377

Livak KJ, Schmittgen TD (2001) Analysis of relative gene expression data using real-time quantitative PCR and the 2(-Delta Delta $\mathrm{C}(\mathrm{T})$ ) method. Methods 25(4):402-408

Macarulla MT, Alberdi G, Gómez S, Tueros I, Bald C, Rodríguez VM, Martínez JA, Portillo MP (2009) Effects of different doses of resveratrol on body fat and serum parameters in rats fed a hypercaloric diet. J Physiol Biochem 65(4):369-376

Manach C, Morand C, Crespy V, Demigné C, Texier O, Régérat F, Rémésy C (1998) Quercetin is recovered in human plasma as conjugated derivatives which retain antioxidant properties. FEBS Lett 426(3):331-336

Matthews DR, Hosker JP, Rudenski AS, Naylor BA, Treacher DF, Turner RC (1985) Homeostasis model assessment: insulin resistance and beta-cell function from fasting plasma glucose and insulin concentrations in man. Diabetologia 28(7):412-419

Pajuelo D, Fernández-Iglesias A, Díaz S, Quesada H, Arola-Arnal A, Bladé C, Salvadó J, Arola L (2011) Improvement of mitochondrial function in muscle of genetically obese rats after chronic supplementation with proanthocyanidins. J Agric Food Chem 59(15):8491-8498

Panchal SK, Poudyal H, Brown L (2012) Quercetin ameliorates cardiovascular, hepatic, and metabolic changes in diet-induced metabolic syndrome in rats. J Nutr 142(6):1026-1032

Perez-Vizcaino F, Duarte J, Jimenez R, Santos-Buelga C, Osuna A (2009) Antihypertensive effects of the flavonoid quercetin. Pharmacol Rep 61(1):67-75

Reagan-Shaw S, Nihal M, Ahmad N (2008) Dose translation from animal to human studies revisited. FASEB J 22(3):659-661

Rivera L, Morón R, Sánchez M, Zarzuelo A, Galisteo M (2008) Quercetin ameliorates metabolic syndrome and improves the inflammatory status in obese Zucker rats. Obesity (Silver Spring) 16(9):2081-2087

Rivera L, Morón R, Zarzuelo A, Galisteo M (2009) Long-term resveratrol administration reduces metabolic disturbances and 
lowers blood pressure in obese Zucker rats. Biochem Pharmacol 77(6):1053-1063

Senese R, Valli V, Moreno M, Lombardi A, Busiello RA, Cioffi F, Silvestri E, Goglia F, Lanni A, de Lange P (2011) Uncoupling protein 3 expression levels influence insulin sensitivity, fatty acid oxidation, and related signaling pathways. Pflugers Arch 461(1):153-164

Shen JZ, Ma LN, Han Y, Liu JX, Yang WQ, Chen L, Liu Y, Hu Y, Jin MW (2012) Pentamethylquercetin generates beneficial effects in monosodium glutamate-induced obese mice and $\mathrm{C} 2 \mathrm{C} 12$ myotubes by activating AMP-activated protein kinase. Diabetologia 55(6): 1836-1846

Somerset SM, Johannot L (2008) Dietary flavonoid sources in Australian adults. Nutr Cancer 60(4):442-449

Srere PA (1969) Citrate synthase. Methods Enzymol 13:3-11

Stewart LK, Soileau JL, Ribnicky D, Wang ZQ, Raskin I, Poulev A, Majewski M, Cefalu WT, Gettys TW (2008) Quercetin transiently increases energy expenditure but persistently decreases circulating markers of inflammation in C57BL/6J mice fed a high-fat diet. Metabolism 57(7 Suppl 1):S39-S46
Szkudelska K, Nogowski L, Szkudelski T (2009) Resveratrol, a naturally occurring diphenolic compound, affects lipogenesis, lipolysis and the antilipolytic action of insulin in isolated rat adipocytes. J Steroid Biochem Mol Biol 113(1-2):17-24

Tai MM (1994) A mathematical model for the determination of total area under glucose tolerance and other metabolic curves. Diabetes Care 17(2):152-154

Vessal M, Hemmati M, Vasei M (2003) Antidiabetic effects of quercetin in streptozocin-induced diabetic rats. Comp Biochem Physiol C Toxicol Pharmacol 135C(3):357-364

Wein S, Behm N, Petersen RK, Kristiansen K, Wolffram S (2010) Quercetin enhances adiponectin secretion by a PPAR-gamma independent mechanism. Eur J Pharm Sci 41(1):16-22

Zabala A, Churruca I, Fernández-Quintela A, Rodríguez V, Macarulla M, Martínez J, Portillo M (2006) trans-10, cis-12 Conjugated linoleic acid inhibits lipoprotein lipase but increases the activity of lipogenic enzymes in adipose tissue from hamsters fed an atherogenic diet. Br J Nutr 95(6):1112-1119

Zhang R, Yao Y, Wang Y, Ren G (2011) Antidiabetic activity of isoquercetin in diabetic KK - Ay mice. Nutr Metab (Lond) 8:85 